\title{
Assessment of Applicability of the Service Design Method on Electric Vehicles
}

\author{
Vanda Orbulov ${ }^{1 *}$, Emma Lógó1 \\ 1 Department of Ergonomics and Psychology, Faculty of Economic and Social Sciences, Budapest University of Technology and \\ Economics, 1111 Budapest, Múegyetem rkp. 3., Hungary \\ * Corresponding author, e-mail: orbulov.vanda@gmail.com
}

Received: 09 May 2019, Accepted: 13 May 2019, Published online: 20 June 2019

\begin{abstract}
The objective of our research work is to assess the applicability of the service design methods on electric passenger cars with special focus on the Central European region. To achieve this goal, the classification and critical evaluation of the key customer touchpoints (such as webpages, showrooms, test drives, events etc.) that could be relevant in the whole sales process are necessary, along with the definition of the sales channel can be dedicated as a key tool of the deeper research. Our further objective is to define such elements of the user experience that are only typical in the case of electric vehicles, therefore they require special process design solutions. As an additional research output, our aim is to highlight the different preferences and needs of the users of electric vehicles compared to the online communication of producers. This could be especially significant in interaction design aspects.
\end{abstract}

\section{Keywords}

service design, design method, customer touchpoint, interaction, user experience, customer experience, electric vehicle, focus group, online communication

\section{Introduction}

The objective of our research work is to assess the applicability of the service design methods on automotive industry with special focus on the possible break points can be an output of involving new aspects in the customer insight phase. Considering the diversity of the car industry our research is limited to markets of electric vehicles (EVs) in the Central European (CE) Countries.

Automotive industry is facing challenges, supposed to be one of the segments that is most involved in a compulsive transition in the near future. If remarkable effect of the sharing economy's and self-driving cars' expansion to our shopping habits would not be enough, impact of massive automatization in car industry (Mraz, 2017) is still able be completed by demonstrative expectation for sustainability. Alternative fueled vehicles have even more importance, dedicated as significant tool for decreasing the carbon-dioxide emission, worldwide Styring et al. (2015). They are not the only editors dedicated carbon dioxide generally as a 'bad' gas, a waste product, and a major contributor to global warming but even more scientific opinions are also directed at this conclusion (Logo, 2013).
There are not so much other segments involving traditional physical and design aspects in such a large proportion as the car industry has (Van Eekeren et al., 2018). Customers of today do not prefer to take material goods anymore, but rather experiences. A strong shift of customer needs towards the intangible products can be observed. Today design process in car industry focuses directly on sales activity by using regular marketing communication tools, while the coverage of the whole life cycle is missing the deep insight activity many times. Insight phase can offer further information that are particularly useful for the sales itself, actually. Success of the market player is mainly based on number of sold cars and not the saved carbon dioxide which can be exchanged to any currency. For achieving the sales numbers market players use traditional marketing tools based on the communication of main features supposed to be important for customers. Basically the success can be defined only by dedicating fix numbers of sales expectation but unless having clear picture about the real intention for the purchase, expected long term market presence cannot be granted for any players. 
However, according to the engineering design lead approach (for classical ways please refer to the findings of Pahl et al. (2007)) focuses not only on the late concept phase, but design happens through development (Sheppard et al., 2017). Some efforts on similar themes have been done by other researchers. For example, Costa, Patrício, Morelli and Magee detail how the application supports the design of product-service systems, highlighting the physical evidence of service, and contributes to advance design research at the intersection of Product-service Systems and Service Design (Costa et al., 2018). For creating proper design thinking-based approach along with defining the user, usually the understanding of the ecosystem of firms representing the market in question is necessary (West and Di Nardo, 2016). This statement holds also for the EV market (furthermore: market) in the Central European countries (furthermore: CE countries). Therefore, our objective is to provide specifications valid for the market, in general.

\section{Methodology}

Design thinking focuses on the customer itself, therefore, it should be also extended to special issues when a relevant product feature is not the main reason of the purchase. The findings and recommendations for taking the customers in the center of Mányai (2008) (for example) are also true for the market. If company prefers to understand its customers and have a real interaction with existing and potential clients, could better understand the reasons of the purchase and to be aware of possible contradictions. Description of methodology covers both the quantitative and the qualitative market research. The problem might be the difference between the classic approach of producers along with supply chain players in their sales process and, the real viewpoints of clients (including their very human thoughts for additional advantages and benefits). Our concept is to analyze these differences based on the list of key features in online offers (web pages).

\subsection{Research plan}

As a research plan our objective is to combine qualitative and quantitative researches along with testing the results of secondary online research in focus groups by having additional information about attitudes and intention. Important output also planned as a comparison of online communication keywords of producers and the real feelings and intentions of interviewed persons.

\subsection{Hypotheses}

In order to make clear conclusions, we defined hypotheses for our researches, as listed below.

- Online marketing communication of producers in CE countries do not show any significant differences.

- Online communication policy has the same identity with real intention of potential and existing EV users.

- Output of a focus group can be also influenced by the special placement and method of the guided interviews.

\subsubsection{Focus groups}

Insight phase based on four focus groups, which allow us to have a clear conclusion based on an appropriate number of interviewed persons. Total number of interviewed persons is thirty-two. Discussions can highlight important details for design thinking including opinion based on preferences, experiences, future plans and information. Information is a key point in our research because our main goal is to explore possible differences between producers' communication (key product advantages) and opinion of customers.

Focus groups of eight are separated into four different teams as following (Table 1). Each team has the same distribution rate of age, gender, education and location (capital or big city of Hungary). Every team has furthermore same distribution (two-two of them) are already owners, potential buyers, persons having antipathy with EVs and ones who have strong motivation of sustainability with no EV.

Interviews were organized in the placement, can have new impact on our research. Our goal was to allow the situation of the interview person absolutely free (sitting,

Table 1 Focus groups

\begin{tabular}{|c|c|c|c|c|c|}
\hline 茔 & 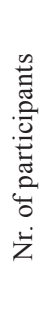 & 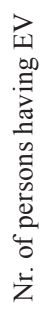 & 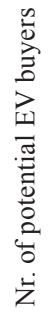 & 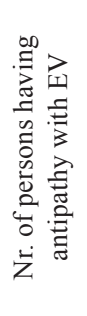 & 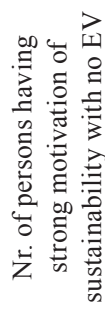 \\
\hline Team 1 & 8 & 2 & 2 & 2 & 2 \\
\hline Team 2 & 8 & 2 & 2 & 2 & 2 \\
\hline Team 3 & 8 & 2 & 2 & 2 & 2 \\
\hline Team 4 & 8 & 2 & 2 & 2 & 2 \\
\hline Total nr. & 32 & & & & \\
\hline
\end{tabular}


standing, moving) in a modern and exclusive place, hoping more information by observing even their body language. Although, more aspects on interviewed person could be observed like the disagreement and discomfort in case of dedicated topics, the clear, provable relationship between the new placement method and outputs cannot be introduced. The main topics for the guide of focus groups were the benefits /problems of:

- parking;

- pricing (grants and financial solutions);

- reducing carbon-dioxide;

- EV as first or second car;

- hybrid or fully electric vehicle;

- main intention of purchasing;

- importance of producers' market positions;

- availability of charging stations;

- sustainability.

\subsubsection{Online communication of producers}

In our research four large producers' products are listed (presented based on gross annual revenue published in 2018). Research does not cover to resellers' marketing activity only to the main online communication channels used directly by producers. Products are sold in four Central European countries (CE countries: Hungary, Slovakia, Poland and Czech Republic). Examined products are fully electric, in the possession of the technology to produce EVs in at least medium series. Reason for specifying examined products as fully electric one is the fact that hybrid vehicles are usually not promoted separately but as an option of the one having internal combustion engines. Advantages of EVs on websites were observed periodically for three months in order to be able to bring any effects of seasonal changes into the examination. Typically, changes on online marketing keywords based on the general seasonal sales campaigns do not fall under the examination as showing absolutely no differences between producers' nor between the EVs and the classical vehicles.

\section{Results and discussion}

\subsection{Results of the online research}

Nomination of products has no relevance from the view of our research, products are differentiated by letters of the English alphabet. Online communication highlights usually some key advantages supposed to be significant during the decision making of customers. All products have three key advantages (Table 2), defined by producers
Table 2 Key advantages used by online webpages of EV producers

\begin{tabular}{lc}
\hline Products & Key advantages communicated online by producers \\
\hline A & range \\
& performance \\
& selection \\
& market leader position \\
B & sustainable \\
& design \\
& market leader position \\
C & sustainable \\
& mobility \\
& city mobility \\
D & price \\
& sustainable
\end{tabular}

on their official landing pages. Keywords focus practically on key advantages suspected to be important for potential users, they are related to the examined written or pictorial presentation. Sustainability, performance and mobility are the most frequent words used by producers in their online communication about studied products.

\subsection{Results of the qualitative research}

Results of focus groups research allowed us to have clear consequences about parallels and conflicts with the output of online research. The rate of mentioned keywords used in online communication and supposed to have high relevance by producers shows a low proportion. Indeed, additional mentioned advantages highlighted the factual intention of a possible taking of an EV (Table 3).

One of further meaningful fact according to our research is that the education and examined location does not have any impact on preferences, although parking has higher importance in the capital than in other cities in Hungary. Only the fact of elder age does not show any special aspects but elder person having at least one car have strong negative opinion of EVs, especially in big cities.

Pricing had the main discussion. Government's grant had not a relevant role for the person have already had an $\mathrm{EV}$, as the rate of the grant is quite low compared to the whole price. Eight interviewed have already bought at least one EV in the last 3 years, 6 of them have a used one (4 of them use a hybrid version) and not a new one, preference was always the price and the fear of short lifetime of battery complemented by the decreasing or unpredictable value of EVs on CE market. Neither leasing solutions were not alternatives, nor other financial solutions. If interviewed were in situation of having the opportunity at 
Table 3 Key advantages compared to the focus group researches

\begin{tabular}{|c|c|c|c|c|}
\hline $\begin{array}{l}\frac{n}{0} \\
0 \\
0 \\
0 \\
0 \\
0\end{array}$ & 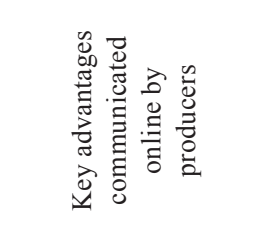 & 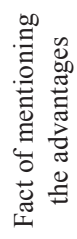 & 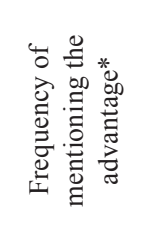 & 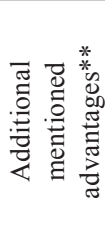 \\
\hline \multirow{3}{*}{ A } & range & $\checkmark$ & $5 / 32 / 16 \%$ & \multirow{12}{*}{ 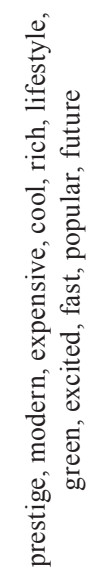 } \\
\hline & performance & $\checkmark$ & $11 / 32(11 \%)$ & \\
\hline & selection & $x$ & & \\
\hline \multirow{3}{*}{ B } & market leader position & $x$ & & \\
\hline & sustainable & $x$ & & \\
\hline & design & $\checkmark$ & $22 / 32(69 \%)$ & \\
\hline \multirow{3}{*}{$\mathrm{C}$} & market leader position & $\checkmark$ & $11 / 32(11 \%)$ & \\
\hline & sustainable & $x$ & & \\
\hline & mobility & $\checkmark$ & $9 / 32(28 \%)$ & \\
\hline \multirow{3}{*}{$\mathrm{D}$} & city mobility & $\checkmark$ & $8 / 32(25 \%)$ & \\
\hline & price & $x$ & & \\
\hline & sustainable & $x$ & & \\
\hline
\end{tabular}

* nr. of mentioning / total number of interviewed person with estimated proportion

** by more than 20 times or more than 20 interviewed

work of choosing between an EV or a classical car as a service car for free, most of them would rather have the classic one referring to range important for traveling abroad.

The fact that the way of producing batteries is not sustainable in every case is only mentioned by persons with strong motivation of sustainability with no EV. Interviewed persons could agree in many cases that $\mathrm{EV}$ is not defined as the best solution for avoiding more and more $\mathrm{CO}_{2}$ emission, but a good tool for starting decreasing and combine the comfortable life with a green one.

All the eight interviewed persons have the EV as a second or third vehicle, all of them have a classical car, having internal combustion engine. So the other person who intent to buy EVs in the next 3 years.

Main intention of purchasing an EV is a key point for our research. Reason for purchasing an EV car is prestige. EVs are expensive, cannot be afforded by everyone. Buying an EV is a privilege of a few, that is the reason why it is valuable according to outputs of our interviews. Buyers and owners do not necessarily behave in an environmentally conscious way in other cases, like usage of packages, transportation, energy usage habits (not including the usage of renewables).

Opinions and discussions about producers and types determine on one hand the insistence on known producers and types, while on the other hand the influence and opinion of colleagues and not the family or friends. The extra services also have an important role at decision but range has the most significant. After having introduced the keywords referenced in our online research, dedicated by producers for customers, only the range and design remained as two main properties have relevant aspects for purchasing. Sustainability and market leader position do not play an important role.

Availability of charging stations are not in the focus in general, however, it can be stated that persons do not have storage possibility at home, would not buy any EVs, even not with a possibility for charging at workplace, this cannot mean an alternative.

Sustainability cannot have a parallel to EVs, motivation determined on different ways. Advantages of EVs are expensive, new and cannot be afforded by all others. One can conclude based on the research that customer groups for EV are different for sustainable products at lower price. Sustainability is an advantage and not the recommended headline in online communication about EVs. Potential buyers are not definitely environmentally conscious; service design should focus on privilege issues: sustainability should not be the headline.

\section{Conclusions}

\subsection{Main conclusion of the research}

Main conclusion is the reason for purchasing an EV car is rather the prestige and not the features like green or fast with even better performance and range. As it was highlighted in point Section 3.2 main reason for purchasing an EV car is prestige. EVs are expensive, cannot be afforded by everyone. Buying an EV is a privilege of a few, that is the reason why is it valuable according to outputs of our interviews. Buyers and owners do not necessarily behave environmentally conscious way in other business. Opinions and discussions about producers and types determine on one hand the insistence on well-known producers and on the other hand the influence and opinion of colleagues and not the family or friends.

First conclusion as a reference to our hypothesis is the operation of same sales and marketing process in all the CE countries. The keywords dedicated to realize the expected sales numbers in these countries are almost the same, unless taking into account the different timing of the government grant which has a quite important role in the communication procedure.

Second conclusion was the conflict between the push massages of producers' and the expectation of user. 
We assume that success of EV market can be improved by recognizing the difference.

Output of a focus group can be also influenced by the special placement and method of the guided interviews. Third conclusion is the importance of output developed

\section{References}

Costa, N., Patrício, L., Morelli, N., Magee, C. L. (2018) "Bringing Service Design to manufacturing companies: Integrating PSS and Service Design approaches", Design Studies, 55, pp. 112-145.

https://doi.org/10.1016/j.destud.2017.09.002

Logo, E. (2013) "Q-Method based environmental awareness measurement in transportation", International Journal for Traffic and Transport Engineering, 3(1), pp. 45-53.

https://doi.org/10.7708/ijtte.2013.3(1).04

Mányai, Cs. (2008) "Instead of Advertising", 21idea Ltd., Budapest, Hungary.

Mraz, S. (2017) "SAE's 6 Levels of Self-Driving Cars", [online] Available at: http://www.machinedesign.com/blog/sae-s-6-levels-self-driving-cars [Accessed: 18 March 2018]

Pahl, G., Beitz, W., Feldhusen, J., Grote, K.-H. (2007) "Engineering Design", Springer-Verlag London, United Kingdom. https://doi.org/10.1007/978-1-84628-319-2 by discussion of a focus group can be also influenced by the special placement and method of the interview; however, statements of clear dedicated differences need to conduct more research.

Sheppard, B., Edson, J., Kouyoumjian, G. (2017) "More than a feeling: Ten design practices to deliver business value", [online] Available at: https://www.mckinsey.com/business-functions/mckinsey-design/our-insights/more-than-a-feeling-ten-design-practices-to-deliver-business-value [Accessed: 18 March 2018]

Styring, P., Quadrelli, E. A., Armstrong, K. (eds.) (2015) "Carbon Dioxide Utilisation", Elsevier, The Netherlands. https://doi.org/10.1016/C2012-0-02814-1

Van Eekeren, R., Wright, S., Čokorilo, O. (2018) "Early cost safety analysis of runway events", International Journal for Traffic and Transport Engineering, 8(3), pp. 261-270. https://doi.org/10.7708/ijtte.2018.8(3).01

West, S., Di Nardo, S. (2016) "Creating Product-service System Opportunities for Small and Medium Size Firms Using Service Design Tools", Procedia CIRP, 47, pp. 96-101. https://doi.org/10.1016/j.procir.2016.03.218 